\title{
The Limits of Planning: Paul Lauterbur
}

\author{
Adam A. Roth BS \\ Richard B. Gunderman MD, PhD
}

\section{Expect the unexpected.}

- Heraclitus

Planning has become one of the bywords of leadership: By failing to plan, you are planning to fail; a goal without a plan is just a wish; without a plan, you are like a ship that has set sail with no destination. Radiology departments and professional organizations invest considerable time, talent, and treasure in strategic planning exercises. However, a great deal of radiology's history and some of its most important breakthroughs were not only unplanned but unintended and even unforeseen.

If radiologists and radiology organizations are to navigate their uncharted futures successfully, they need to distance themselves from the mistaken notions that all good things are planned and that flourishing is correlated with the degree to which it is planned out in advance. In many cases, failure results less from a lack of planning than an inability or unwillingness to recognize and respond effectively to unexpected problems and opportunities. Numerous fallen giants in radiology, such as EMI and Kodak, stuck to their plans far too long $1,2$.

Consider, for example, one of the most important innovators in radiology — the late Paul Lauterbur. To planning's advocates, it might seem obvious that the person most responsible for the single greatest innovation in radiology over the past 50 years must have set off with a clear plan of inventing MRI, but the opposite is far closer to the truth. What makes Lauterbur particularly remarkable is not the role of serendipity in his story but the modesty and circumspection he exemplified in telling it.

This is the author's manuscript of the article published in final edited form as: 


\section{Lauterbur's “Official Story”}

Paul Lauterbur shared the 2003 Nobel Prize for Medicine or Physiology with Britain's Peter Mansfield. A professor at the State University of New York at Stony Brook from 1963 to 1985 and then the University of Illinois Urbana-Champaign for the final 22 years of his life, Lauterbur's work built on the foundations of Felix Bloch and Edward Purcell, who received the 1952 Nobel Prize in Physics for the development of nuclear magnetic resonance (NMR), which had been used for decades in studying the structure of chemical compounds.

Lauterbur was educated at Case Western University, then assumed a position at Dow Corning. His work there was interrupted by a stint in military service at the Army Chemical Center. Returning to the Mellon Institute in Pittsburgh, he pursued graduate study in chemistry at the University of Pittsburgh, earning his $\mathrm{PhD}$ in 1962 . He then accepted a faculty position at Stony Brook. During the 1970s, Lauterbur undertook the NMR research that, 30 years later, would garner him a share of the Nobel Prize.

Lauterbur realized that introducing gradients into the magnetic field would enable him to determine the spatial coordinates of nuclei whose radio signals the NMR device was detecting, which could be used to produce two-dimensional images of an object. Some of the early objects he imaged included clams that his daughter had collected along a Long Island beach, as well as two test tubes of heavy water in a beaker of ordinary water [3]. Mansfield built on Lauterbur's initial work by using frequency and phase encoding to reduce artifacts and speed up the imaging process [4].

\section{Lauterbur's Serendipitous Path}

Lauterbur was not a particularly distinguished student. His rather uneven grades in elementary and middle school convinced his parents that he should purse a technical track in high school. He did, however, love experimentation. As a high school student, he built a laboratory in his parents' basement, and over the course of a summer, he read a chemistry book on his own. Lauterbur was as surprised as anyone when, as 
a junior, he received the top score on a statewide chemistry examination, which convinced everyoneincluding him — that he should go to university.

Lauterbur was following not a plan but his passion, and by the time he completed his undergraduate degree in chemistry, he felt that he had had his fill of academic work. He decided not to pursue graduate studies. The topic of his undergraduate research on chemical bonding led to a job at Dow Corning. There his bosses saw his research potential and, disregarding his lack of interest in an investigative career, they sent him to their research facility in Pittsburgh. Lauterbur did not get what he wanted, but it turned out to be what he needed.

Lauterbur was interested not in NMR but the role of free radicals in vulcanization [5]. However, while he was working on these experiments, two unexpected things happened. First, an article was published on the use of NMR in the study of polymers [6]. Second, a pioneer of NMR use in chemistry [7], Herbert Gutowsky, gave a seminar on the use of NMR in the study of the chemical structure of methane. Lauterbur reached out and arranged to send chemicals he synthesized to Gutowsky in Illinois for NMR analysis. But soon thereafter, Lauterbur was drafted for military service.

The Army, recognizing Lauterbur's expertise, assigned him to its Chemical Center in Maryland, where he initially worked on cholinesterase inhibitors. But when he discovered that a nearby laboratory had residual funds in its budget to invest in a state-of-the-art NMR device, he persuaded his supervisor to transfer him there. He soon learned that he was the only scientist in the laboratory who knew how to use NMR. The discovery of a manufacturing defect in the device left him with time on his hands, so he went to Johns Hopkins to read everything he could on NMR. Armed with this knowledge and a functioning NMR device, his name appeared on four basic-science NMR publications.

By now, Lauterbur's interest in research had been completely rekindled. Back at Dow Corning, he conducted nationally recognized research in heteronuclear NMR [8]. He was asked to write book chapters despite the fact that he possessed only a bachelor's degree [9]. One day, he asked to attend the Faraday 
Society meeting in England. Encountering initial resistance, he offered to pay his own way and use his own vacation time to do so. However, continuing reluctance convinced him that he needed to leave industry, so he completed his doctoral studies at Pittsburgh [10]. Had his employer agreed to let him attend the meeting and lent more support to his research interests, it is quite possible that he would not have completed his $\mathrm{PhD}$ and would have stayed in industry.

Lauterbur's big breakthrough occurred in the most unlikely of places, a suburban Pittsburgh Big Boy restaurant. There, between bites of a hamburger, the idea of using a gradient magnetic field to code for spatial location first occurred to him [11]. He scribbled his first model on a table napkin. He later purchased a college-ruled composition book into which he entered his ideas over a 6-day period between September 2 and 7 of 1971, ensuring that each page was signed, dated, and witnessed to document his priority [12].

While Lauterbur was on faculty at Stony Brook, he lacked direct access to the best NMR device on campus. The only way he could get time on the machine was to conduct his experiments at off-hours, meticulously restoring the device to the chemists' settings after each night's work. Lauterbur showed that his technique could produce two-dimensional images. Said a colleague of one of his NMR images of a clam, "It looked pretty much like a clam." But the relevance and importance of the work remained unclear, and many deemed his work "sort of wacky."

Lauterbur submitted his results to the journal Nature, but his manuscript was rejected. Unlike most authors, Lauterbur persisted. Eventually, the editors granted his appeal, later accepting a revised manuscript [13]. It was published in 1973 as "Image Formation by Induced Local Interactions: Examples Employing Nuclear Magnetic Resonance" [3]. It is now recognized as a classic. Lauterbur would later famously say of the rejection, "You could write the entire history of science in the last 50 years in terms of papers rejected by Science or Nature"[10]. 
Lauterbur's subsequent career continued to expose the limitations of planning. For example, Stony Brook refused to give him priority on its NMR devices or to help him patent his discoveries. When he moved to Illinois, partly to ensure an academic appointment for his wife, he was promised a large start-up package, but many promises failed to materialize. Incredibly, Lauterbur ended up losing both his medical school equipment and laboratory, and he was eventually forced to seek refuge in the chemistry department.

\section{Planning}

Planning has many limitations. For one thing, it can be a time-consuming, labor-intensive, and costly process that does not guarantee success and may in some cases tend to preclude it. For example, time spent planning can undercut creativity, in part by contributing to the mistaken presumption that all good things must be foreseen and intended. Even more problematically, planning's benefits tend to be diminished in a highly dynamic setting. Finally, and perhaps most importantly, planning can foster inflexibility and a failure to adapt to new problems and opportunities.

The career of the greatest innovator in radiology in the past 50 years is less comprehensible as a wellformulated and executed plan than as an adventure full of unexpected twists and turns. What distinguished Lauterbur was not the sophistication of his planning but his deep curiosity, his willingness to follow where circumstances seemed to be leading, and his dogged persistence in the face of disappointment and dismissal. He did not set out by imagining what he would discover, but in the words of Louis Pasteur, he possessed the kind of prepared mind that chance seems to favor.

If the stories of great innovators such as Lauterbur cannot be told in terms of planning, why does planning retain such popularity? Part of the answer lies in our need to believe that our careers are the product of our own volition, and that we deserve all the credit for our success. Another reason lies in the fact that planning is big business, and there is far more money to be made facilitating planning exercises than in pointing out the limitations of planning. Finally, too little attention is paid to stories such as Lauterbur's and the spirit of adventure they foster. 
Lauterbur's story reminds us that what radiology often needs is not more frequent or elaborate strategic planning exercises, many of which merely end up moldering on a shelf, but a greater appreciation for preparing minds for discovery and allowing them to pursue unexpected opportunities. One of the most important resources in this regard consists of the stories of great figures in the history of radiology, for whom serendipity's role can hardly be exaggerated. Exploring the stories of predecessors represents one of the best forms of preparation for future radiologists. 


\section{References}

1. Alexander RE, Gunderman RB. EMI and the first CT scanner. J Am Coll Radiol 2010;7:778-81.

2. Gavetti GM, Henderson R, Giorgi S. Kodak (A). Harvard Business School Case 703-503. 2003.

3. Lauterbur PC. Image formation by induced local interactions: examples employing nuclear magnetic resonance. Nature 1973;242:190-1.

4. Mansfield P, Maudsley A. Medical imaging by NMR. Br J Radiol 1977;50: 188-94.

5. Warrick E, Lauterbur P. Filler phenomena in silicone rubber. Industrial \&Engineering Chemistry $1955 ; 47: 486-91$.

6. Holroyd L, Codrington R, Mrowca B, Guth E. Nuclear magnetic resonance study of transitions in polymers. J Appl Phys 1951;22:696-705.

7. Jonas J, Slichter C. Herbert Sander Gutowsky. Biographical Memoirs, 88. Washington DC: National Academies Press; 2006.

8. Lauterbur PC, Kurland RJ. On the signs of $\mathrm{CH}$ and $\mathrm{HH}$ coupling constants. J Am Chem Soc $1962 ; 84: 3405-6$.

9. Lauterbur PC. Nuclear magnetic resonance spectra of elements other than hydrogen and fluorine. In: Determination of organic structures by physical methods 1962;2:465.

10. Dawson MJ. Paul Lauterbur and the Invention of MRI. Cambridge, MA: MIT Press; 2013.

11. Lauterbur PC. One path out of many_how MRI actually began. In: Grant DM, Harris RK, eds. Encyclopedia of magnetic resonance. Chichester, UK: John Wiley and Sons; 1996:445-9.

12. Lauterbur PC. Paul C. Lauterbur notebook. 1971. Available at: https://digital.sciencehistory.org/works/0c483j46q. Accessed September 10, 2018. 
13. Lauterbur PC. All science is interdisciplinary-from magnetic moments to molecules to men (Nobel lecture). Angew Chem Int Ed Engl 2005;44:1004-11. 